\title{
As características dos jornais como poder cultural: releituras da teoria do jornalismo proposta por Otto Groth
}

The characteristics of newspapers as cultural power: reinterpretations of journalism theory proposed by Otto Groth

Las características de los periódicos como poder cultural: relecturas de la teoría del periodismo propuesta por Otto Groth

DOI: $10.1590 / 1809-5844201922$

\author{
Cintia Xavier ${ }^{1}$ \\ https://orcid.org/0000-0002-8355-1718 \\ Felipe Simão Pontes ${ }^{2}$ \\ https://orcid.org/0000-0003-1377-2272
}

${ }_{1}^{1}$ (Universidade Estadual de Ponta Grossa, Setor de Ciências Sociais e Aplicadas, Programa de Pós-Graduação em Jornalismo e Programa de Pós-Graduação em Ciências Sociais Aplicadas. Ponta Grossa - PR, Brasil).

${ }^{2}$ (Universidade Estadual de Ponta Grossa, Setor de Ciências Sociais e Aplicadas, Programa de Pós-Graduação em Jornalismo. Ponta Grossa - PR, Brasil).

\section{Resumo}

O jornalismo, como um produto cultural que resulta de necessidades sociais, é objeto de sistemática e complexa exposição por parte de Otto Groth. O objetivo deste texto é analisar as vinculações que o autor estabelece das características do jornalismo com a cultura, entendendo o jornal como materialização especializada de sentidos presentes na sociedade. Em revisão de textos que estudam a obra de Groth, identificamos a ausência de reflexões sobre o arcabouço neokantiano que estrutura as proposições do autor. Neste ensejo, apresentamos uma análise conceitual da ciência jornalística como ciência do espírito, para depois explorar as características dos jornais: periodicidade, atualidade, universalidade e publicidade.

Palavras-chave: Otto Groth. Epistemologia. Jornalismo. Cultura. Características dos Jornais.

\begin{abstract}
Journalism, as a cultural product resulting from social needs, is the subject of systematic and complex exposition by Otto Groth. The purpose of this text is to analyze the links that the author establishes between the characteristics of journalism and culture, understanding the newspaper as a specialized materialization of senses present in society. In reviewing texts that study Groth's work, we identify
\end{abstract}


the absence of reflections on the neo-Kantian framework that structures the author's propositions. In this occasion, we present a conceptual analysis of journalistic science as a science of the spirit, to later explore the newspaper's characteristics: periodicity, actuality, universality and publicity. Keywords: Otto Groth. Epistemology. Journalism. Culture. Newspaper’s characteristics.

\section{Resumen}

El periodismo, como producto cultural resultante de las necesidades sociales, es objeto de una exposición sistemática y compleja de Otto Groth. El objetivo de este texto es analizar los vínculos que el autor establece entre las características del periodismo y la cultura, entendiendo el periódico como una materialización especializada de los sentidos presentes en la sociedad. Al revisar los textos que estudian el trabajo de Groth, identificamos la ausencia de reflexiones sobre el marco neo-kantiano que estructura las proposiciones del autor. En esta ocasión, presentamos un análisis conceptual de la ciencia periodística como una ciencia del espíritu, para luego explorar las características del periódico: periodicidad, actualidad, universalidad y publicidad.

Palabras-clave: Otto Groth. Epistemología. Periodismo. Cultura. Características del Periódico.

\section{Introdução}

Em mais de 50 anos de carreira, Otto Groth desenvolveu vasta obra para explicar a história e a natureza do jornalismo. A principal foi "O poder cultural desconhecido: fundamentos da Ciência dos Jornais”, composta por sete tomos (um inacabado) e mais de 2.000 páginas, publicada de 1961 a 1966.

Possivelmente, a maior limitação do conjunto de textos de Groth seja a sua não circulação em língua inglesa ou francesa. As ideias de Groth foram discutidas em língua espanhola a partir de uma sintética análise realizada por Faus Belau (1966), texto estudado no Brasil a partir dos anos 1970, em especial por um texto de Bueno (1972) realizado no âmbito da Universidade de São Paulo - e que circulou entre estudiosos brasileiros do jornalismo. O aumento da divulgação e de estudos sobre os textos de Groth ocorre no país a partir de 2007, com a tradução de "A tarefa da pesquisa científica sobre a cultura”, primeiro capítulo de "O poder cultural desconhecido", realizada em coletânea organizada pelas professoras Christa Berger e Beatriz Marocco. A produção de artigos e reflexões sobre Groth no Brasil aumentou diante da própria expansão das pós-graduações em Jornalismo e de linhas de pesquisa específicas nos Programas de Comunicação. E se consolidou com a tradução de três capítulos de “O poder cultural desconhecido” em 2011.

O ensejo deste texto está circunscrito às limitações de acesso à obra de Groth e tomamos por referência os textos do autor traduzidos para o português, bem como intérpretes de língua portuguesa e espanhola. Ainda assim, acreditamos que nossa tarefa permanece válida, uma vez que nos propomos a realizar um exercício de análise teórica. Perscrutamos as vinculações que o autor estabelece das características do jornalismo com a cultura de uma dada comunidade, entendendo o jornal como materialização especializada 
de sentidos presentes na sociedade. Sob esse aspecto, exploramos as características dos jornais: periodicidade, atualidade, universalidade e publicidade, tendo por pressuposto o entendimento da proposta de Groth no arcabouço teórico-filosófico neokantiano.

\section{Para entender o escopo epistemológico}

Ao se analisar as exegeses brasileiras sobre o texto de Groth e, principalmente, sobre as características centrais da ciência jornalística proposta por ele, percebemos três principais formas de entendimento. Primeiramente, estudos mais empíricos, em que os conceitos de periodicidade, universalidade, atualidade e publicidade são apresentados para compreender sua possível aplicação a produtos jornalísticos (do passado ou do presente), principalmente produções realizadas a partir de novas tecnologias digitais.

O segundo conjunto de textos tem característica crítica, entendendo tanto as concepções como o léxico mobilizado pelo autor como "positivista”, "mecânico” ou "limitante” diante da diversidade de manifestações do jornalismo. Muito devido ao modo como é realizada a classificação das características e sua aplicação a produtos jornalísticos pela primeira forma de entendimento explicitada, os textos críticos apresentam que a proposição de Groth limita-se ao entendimento do veículo jornal impresso. O léxico que Groth mobiliza e sua afirmação da existência de uma "Ciência dos Jornais" são catalogados como positivistas, uma vez que trabalha com conceitos como essência, normas, método, contemplação, objetivo, que, na visão de alguns desses textos, não atenderia a narratividade, a subjetividade, a criatividade, as limitações, a parcialidade e a diversidade de manifestações do jornalismo.

Alguns outros textos (o terceiro conjunto) destoam das duas primeiras exegeses. São análises que destacam a estrutura weberiana do pensamento de Groth ${ }^{1}$, com ênfase para a referência de que Weber foi professor de Groth, de que é o autor mais citado por ele no capítulo sobre "A tarefa da pesquisa científica sobre a cultura", da utilização de conceitos como causalidade, tipo ideal e sentido, e pela própria forma como Groth constrói o objeto da ciência dos jornais - parecida com o mesmo movimento realizado por Weber para as ciências sociais (OLIVEIRA, 2014). Entendemos que este último conjunto de análises sobre o texto de Groth aproxima-se mais de seu arcabouço teórico filosófico. Porém, não localizamos, neles, explorações sobre os nexos entre conceitos estruturantes da ciência proposta por Groth e as características da ciência jornalística. Localizamos em Groth uma proposta com influências weberianas e, por isso, deve ser entendido como pertencente à tradição neokantiana de formulação da especificidade das Ciências do Espírito ou de Ciências da Cultura. Cabe lembrar que Weber também faz parte dos autores que discutem as teses kantianas para as Ciências Humanas (neokantianos). Porém, ainda que Groth utilize conceitos e a estrutura conceitual/ metodológica weberianos, entendemos que, epistemologicamente, há peculiaridades em sua acepção que necessitam de esclarecimentos.

1 Ainda que muitos críticos à obra de Weber o considerem positivista, consideramos um equívoco realizar um curto-circuito de conceitos de Comte e Durkheim com os de Weber. 
Rüdiger (2017), por exemplo, afirma que Groth não trabalha operativamente com o conceito de ação social para a explicação da ciência jornalística. Rüdiger (2017) também defende, ainda que ligeiramente, que o pensamento de Groth é similar à teoria das formas simbólicas de Cassirer, em específico com suas explicações sobre as ciências da cultura. Mesmo que a hipótese de influência de Cassirer sobre Groth seja importante para entendimento de sua proposição para a ciência jornalística de modo geral e para as características do jornal de modo específico, há de se considerar que Cassirer é mencionado apenas em um trecho sobre o método em “Tarefa da Pesquisa Científica sobre a Cultura”, texto ao qual Rüdiger (2017) dedica análise.

Ao estudarmos trecho em que Groth apresenta sua definição da ciência jornalística como uma ciência do espírito ou da cultura, é a Dilthey a quem faz referência. Dilthey (1949; 1968) defende que as ciências do espírito devem ser compreendidas distintamente das ciências naturais ou físicas. Essa distinção ocorre pelo objeto e pelo método. Ao diferenciar ciências do espírito e ciências naturais pelo objeto, Dilthey defende que as primeiras se interessam pelos fatos morais, "em que o objeto se apresenta do interior, como experiência de um conjunto vivo original” (REIS, 2003, p. 102). Trata-se de uma estrutura íntima da vida, psíquica, que se apresenta como uma unidade, com uma sistematicidade que se mostra em suas externalidades (percepções, imagens, sensações). Essa estrutura constitui-se como unidade ao resistir às externalidades, produzindo distinções, identificações, associações e separações dela própria. Quer dizer, o objeto vai se definindo e constituindo unidade ao se tornar autônomo. "É deste mundo do espírito objectivo que o nosso eu recebe, desde a primeira infância, o seu alimento” (DILTHEY, 1968, p. 262). Seguindo sistematização de Reis (2003), a terceira diferenciação quanto ao objeto está não na égide da lei da causalidade como defendem as ciências naturais, mas no entendimento da finalidade (telos) que dirige a ação psíquica. Sob esse aspecto, o moral ou o espiritual são processos interiores associados segundo uma finalidade (DILTHEY, 1968; REIS, 2003). Dilthey (1968) argumenta que a sociedade, como mundo humano exterior, surge pela transferência da vida psíquica do indivíduo para os outros indivíduos, entendendo que o conjunto de fatos morais difere da natureza por sua grande organização em sistemas teleológicos dominados pela vontade. Isso não significa que ele está tratando no âmbito de uma "metafísica teleológica”, mas que o objeto das ciências do espírito é a vida objetivada, o processo mental individual e coletivo objetivados.

Quanto ao método, Dilthey (1968) defende a diferença de formas de “contemplação" do mundo da vida como principal recurso para a definição de uma ciência. Nas ciências do espírito, os pesquisadores “compreendem” os processos interiores em sua manifestação exterior, pois essa manifestação exterior é um aspecto da interioridade. Diferente das ciências naturais, que explicam as leis exteriores, sem a preocupação em compreender a estruturação e manifestação do sentido. Essa distinção entre compreender e explicar atravessa todos os autores neokantianos a partir da proposição de Dilthey, com diferenças de entendimento, mas com igualdade de termos e problemática - vemos isso em Rickert, Wildeband, Weber 
e em um conjunto de estudiosos das ciências sociais e históricas do final do século XIX e início do XX (PONTES, 2009).

Um segundo aspecto do método, a proposição de Dilthey é individualista - baseia-se na compreensão do sentido de ações individuais e não numa filosofia da história da qual a ideia seria um ente metafísico supra histórico que determinaria as ações individuais - tanto em sentido idealista hegeliano, quanto no sentido evolucionista comtiano (REIS, 2003). "É no interior dos conjuntos interativos sociais concretos que se deveria tratar a questão do sentido” (REIS, 2003, p. 134).

O objeto das ciências do espírito é a “objetivação da vida”. Dilthey (1968) designa a objetivação da vida de “espírito objetivo”. Diferente de Hegel, que define espírito objetivo como uma etapa do desenvolvimento do espírito universal (especulativo, metafísico), para Dilthey (1968, p. 262), o espírito objetivo refere-se à realidade da vida, “[...] aos costumes, ao direito, ao estado, à religião, à arte, às ciências e à filosofia [...]”. Há uma hierarquia de entendimento que vai da mais indeterminada - quando tratamos da humanidade de modo geral -, até a mais determinada, as ações restritas, individuais. É com o arcabouço metodológico das ações determinadas, para Dilthey, que “compreendemos” as manifestações do espírito das manifestações mais indeterminadas e complexas. Ademais, ações individuais resultam do espírito objetivo e entender a estruturação do complexo ao individual exige a compreensão desse espírito objetivo. O que nos leva a Groth (2011, p. 33 - Grifos do autor).

Jornais e revistas são obras culturais. Cultura é entendida aqui como o conjunto das criações mentais humanas que cresce e muda continuamente. Assim, a Ciência dos Jornais é a ciência de obras culturais, é uma "ciência da cultura”. A interdependência na qual o mundo imaterial se encontra e se diferencia da causalidade da natureza pelo fato de que esta interdependência leva a valores e finalidades a cabo de acordo com a estrutura da mente. E na verdade, não ocasionalmente, não aqui e lá, mas está justamente na estrutura do intelecto o gerar valores e o concretizar fins na sua influência recíproca sobre a base do compreender.

Groth (2011, p. 32 - Grifos do autor) entende que “todo pensar e agir humano é final, ocorre por causa da satisfação das necessidades das finalidades estabelecidas”. Sob esse aspecto, continua Groth (2011, p. 33), “a obra cultural tem, como a realização de um sentido, uma 'realidade sensorial', ela é, portanto, voltada teleologicamente para os seres humanos, para os sujeitos. A sua estrutura é subjetiva/objetiva como um todo e em suas partes”. Ele busca reconhecer a jornalística como uma ciência autônoma a partir do reconhecimento da especificidade de seu objeto e de seu método. E o faz para reconhecer uma "uniformidade interna específica”, um sentido cultural que se especializa e determina a manifestação de objetos empíricos que lhe fazem alusão. 
Se nós, portanto, partirmos primeiro das semelhanças externas dos objetos nas primeiras sínteses provisórias, esta conexão teleológica continua não sendo determinante, mas é um sinal do conjunto do sentido, da similaridade das finalidades às quais os objetos servem, e da uniformidade interna determinada por esta similaridade. Se nós quisermos uma ciência cultural própria dos jornais e das revistas, então nós temos que buscar primeiro esta uniformidade interna específica e depois formular os nossos problemas e conceitos, e não pesquisar os conteúdos políticos históricos ou as formações “literárias” dos jornais e revistas. Estes objetivos já são buscados por outras ciências, podem ou devem ser buscados por elas e os resultados a serem obtidos assim só interessam à Ciência dos Jornais em segundo plano. [...] Mas para uma Ciência dos Jornais, o "essencial”, ou seja, o importante fundamentado, é exclusivamente a "ideia”, a "essência”, a "natureza” das obras - a similaridade do seu sentido, seus lados considerados essenciais, suas qualidades constantes, as “características” e a estrutura desta unidade - e o que está ligado a isto. É no essencial que ela tem o seu objeto e o seu método próprio, ele fundamenta o sistema dela. A investigação do essencial gera a ciência da cultura “Ciência dos Jornais” (GROTH, 2011, p. 34-35).

Assim, a tarefa da ciência jornalística é reconhecer o sentido, a finalidade da obra, sua interioridade - bem ao sentido de Dilthey. "A aparência, ou seja, a produção técnica não tem importância nenhuma para a definição dos conceitos e para a delimitação do objeto" (GROTH, 2011, p. 36 - Grifo do autor). Sob esse aspecto, a crítica a Groth de que sua teoria somente tem validade para o jornal impresso carece de fundamento e revela desconhecimento de sua matriz conceitual. “Assim, a essência do jornal permanece a mesma, indiferente da materialização na qual se manifesta, se em papel impresso, letras na parede ou em palavras no rádio” (GROTH, 2011, p. 36).

A vinculação à concepção de ciências do espírito de Dilthey serve para compreendermos a estrutura do raciocínio de Groth. Porém, Groth também se distancia de Dilthey. Principalmente ao conceber o método da pesquisa nas ciências da cultura. É onde o autor busca avançar na divisão diltheyana de ciências do espírito e ciências naturais. Dizer que há um fundamento de objeto e de método nas ciências da cultura diante das ciências naturais para, depois, buscar pontos de conexão entre elas é muito comum entre os autores neokantianos. Assim como faz Weber, Groth expõe que o método das ciências da cultura é o compreender, mas o pesquisador precisa trabalhar com as causalidades. Se, como afirma Hartmann, somos sujeitos com sentido que mobilizam causalidades para atender as finalidades, o desconhecimento das causas interfere diretamente na concreção dos fins (LUKÁCS, 2012; GROTH, 2011). Portanto, para Groth, a Ciência Jornalística precisa entender as causalidades que lhe são externas e pertinentes para entender as regularidades do sentido.

Todo esse excurso, mais do que cravar a influência de Dilthey sobre Groth, quer demonstrar que o desenvolvimento da ciência jornalística por ele proposta acontece sob o 
arcabouço neokantiano. Essa localização da proposta de Groth está manifesta claramente em várias passagens, como ao ele estabelecer as classificações de ciências com base em Wildeband, Rickert ou Husserl. Entendemos que somente com essa base é que podemos avançar para analisar as características dos jornais e reorganizar a interpretação da proposição do teórico.

\section{As características dos jornais}

Dentre os conceitos mais difundidos da obra "O poder cultural do desconhecido", estão as características dos jornais. Entendemos, seguindo raciocínio já esboçado, que as características somente podem ser compreendidas na sua relação com a interioridade da obra, com o sentido. Groth explica que as características não são o sentido, mas são partes, decomposição do todo que se mostra sistematizado e objetivado na vida prática, auxiliam a apreensão, mas que, se isoladas, perdem sua razão de ser no sentido.

Elas são trabalhadas por Groth a partir do conceito de tipo ideal de Weber. O tipo ideal é uma categoria construída pelo analista que permite se aproximar da realidade e reconhecer racionalmente elementos que estão, em um primeiro momento, desconexos, mas são recorrentes. São construtos, por isso, não presentes na realidade no modo como descritos, pois “exageram” aspectos, oferecem idealizações ou plenitude que possibilitam ao analista estabelecer contrastes com a realidade prática observada.

As quatro características apresentadas são periodicidade, universalidade, atualidade e publicidade. Elas não são elementos justificáveis pelo produto jornal, mas por finalidades da sociedade e da história. Groth propõe uma inversão do raciocínio, pois as características não são um catálogo para classificar a realidade dos jornais, ou seus produtos, mas servem para entender finalidades da comunidade para a qual o jornal é produto, cristalização. As características do jornal são respostas a necessidades sociais e, como tais, precisam ser compreendidas, pois papel, bite, imagem, som não são o jornalismo, são meios que somente ganham o sentido jornalístico na manifestação dessas finalidades na qual o jornal (independente do meio) está inserido. Essas finalidades da cultura, espírito objetivado, é histórico e varia de região para região.

O jornalismo tende a responder a cada local com os recursos e necessidades de sua comunidade. Isso significa que periodicidade, universalidade, atualidade e publicidade são categorias analíticas sob a forma de tipo ideal, que ajudam a compreender as características jornalísticas de dada comunidade/sociedade cristalizadas em produtos (jornal, radiojornal, telejornal). Por isso, Groth define os jornais como "obras culturais”. "Mas os números de um jornal impresso, as sucessivas emissões dos jornais radiofónicos ou televisivos não são partes do jornal enquanto jornal, apenas emanações ou materializações da sua realidade ideal” (FIDALGO, 2004, p. 3).

Groth defende que a periodicidade é a mais imediata das características do jornal, ao estabelecer uma conformação do ritmo do público materializado na produção sistemática da 
informação. Universalidade e atualidade são características que se cristalizam no conteúdo dos jornais. E a publicidade é resultado do vínculo do produto com a comunidade. A partir dessas considerações, passamos às características e aos aspectos que elas oferecem para entendimento do jornalismo segundo Groth.

\section{Periodicidade}

A primeira característica que aparece ao se estudar os jornais é a periodicidade. “O que caracteriza antes de mais o jornal é a sua aparição periódica” (FIDALGO, 2004, p. 3). Tal categoria está centrada na sua forma, sem observar os conteúdos que o jornal produz. A personalidade de um jornal vai ser estabelecida pela continuidade das suas emanações publicadas periodicamente. Os períodos guardam relação com o espaço e com o tempo. O período tem relação com o caminho, “[...] a distância que se circula ou se percorre, ou seja, um ciclo, percurso [...]” (GROTH, 2011, p. 150).

O retorno periódico é uma qualidade para todo jornal. A periodicidade é uma relação com o sujeito, com a cultura, está ligada à necessidade e prevê regularidade (GROTH, 2011). “A medida da periodicidade, os espaços de tempo e as horas do dia nos quais os números do jornal são publicados são determinados pelos propósitos das pessoas” (GROTH, 2011, p. 150-151). O ritmo do jornal se estabelece a partir do sujeito moderno, que se tornou pontual sob a pressão da concorrência capitalista. A implementação tecnológica da vida em sociedade reconfigura o processo de produção do jornal. “Os períodos do jornal só se tornaram constantes quando a técnica e a organização da notícia possibilitaram o recebimento regular, seguro do material, quando a técnica de impressão permitiu a reprodução rápida e o correio e o trem também propiciaram a propagação imediata” (GROTH, 2011, p. 161).

Ao tratar das possibilidades técnicas e do recebimento regular, o autor aponta aqui a publicidade como um dos eixos que sustenta a periodicidade. Para ser periódico, o jornal precisa circular regularmente para os seus leitores. Fidalgo (2004) aponta para a periodicidade como uma relação entre o fato (acontecimento) e sua publicização, ampliando o sentido dessa característica para além do impresso. "Mais marcante para a periodicidade jornalística é a simultaneidade e não a regularidade” (FIDALGO, 2004, p. 4). Isso acontece porque a própria produção de acontecimentos (sistemáticos ou imprevistos) demarcam e interferem no ritmo do público. "A medida dos períodos na realidade varia de acordo com as pessoas que produzem, segundo as suas condições naturais e socioculturais” (GROTH, 2011, p. 161).

Groth (2011) explica que o jornal, inicialmente, preocupava-se com respostas imediatas aos interesses de uma dada comunidade por informações e dar a conhecer acontecimentos específicos. O jornal, sua organização e sistematicidade, passa, em um segundo momento, a interferir publicamente, como produto da vontade política, interferindo na conformação de opiniões que circulam periodicamente. No terceiro momento, o jornal adquire sistematicidade 
e passa a responder ao gênero, ao sentido público, com institucionalidade e universalidade, conformando-se em períodos mais integrados à cultura.

Ao formular o conceito, Groth (2011) chama de jornal uma ideia completa, formada por uma realidade imaterial, que nunca se torna visível. Materializa-se, por exemplo, em números ou exemplares. Ao tratar da publicação de exemplares, apresenta um dos requisitos da periodicidade: oferecer um material publicado a cada espaço de tempo, de acordo com a realidade na qual está inserido. "Só exemplares materializados de alguma forma podem ser perceptíveis aos sentidos” (GROTH, 2011, p. 147). Porém, como já destacamos, o jornal é imaterial e único e, ao mesmo tempo, é esta unidade que resulta na continuidade. "Ele (o jornal) só é apreensível por meio de cada número e exemplar, das ações tomadas para a sua produção e das organizações geradas para isto e assim por diante” (GROTH, 2011, p. 147). Ao selecionar os assuntos que compõem um exemplar, Groth expõe a necessidade de compreensão da universalidade e aponta que a atualidade está posta no interior da periodicidade. Sempre tendo em vista que, para potencializar um possível "efeito de sentido" no contexto em que está inserido, o jornal necessita tornar-se público - em relação com a característica publicidade - circular com regularidade condição para a publicidade.

\section{Universalidade}

A existência do jornal, como tal, está determinada pela universalidade e suas questões são observadas nos conteúdos dos jornais. Para formular o conceito de universalidade, Groth (2011) recupera o debate da ciência da cultura para apontar que o ser humano está inserido num mundo objetivo. O compartilhamento do mundo físico e social do ser humano, a interação com o mundo, formular opiniões e posições ocorre por vários aspectos. "No entanto, ninguém absorve tudo o que há no mundo diante de si com o mesmo sentimento e o mesmo interesse, com a mesma participação e o mesmo compartilhar” (GROTH, 2011, p. 168). O universal deve vir da amplitude de assuntos possíveis para serem tratados num determinado jornal (FIDALGO, 2004, p. 9).

Fidalgo (2004, p. 5), ao tratar da universalidade em Groth explica que: "Não é o mundo em si, mas o mundo tal como o homem o enfrenta, como determina o homem e como o próprio homem por sua vez o determina”. O mundo objetivo, portanto, é um conceito relacional. O conceito de universalidade está associado à realidade objetiva (inatingível) um tipo ideal.

A necessidade de estar situado, no tempo e no espaço, inserido no mundo social e na cultura, faz com que o jornal seja resultado da conexão do ser humano com o mundo social. Por isso, para situar o homem moderno, o jornal precisa ser universal. “O jornal capacita o homem moderno com tudo o que precisa para encontrar-se e afirmar-se na engrenagem complicada da sociedade moderna de hoje” (GROTH, 2011, p. 218). A universalidade corresponde ao aspecto socializador da comunidade e guarda uma tripla relação: “eu e os 
outros”, “eu e a natureza” e “eu e o mundo” (FAUS BELAU, 1966). Em cada indivíduo, fenomenologicamente, se estabelecem conexões para cada uma das relações. Os jornais têm, por tarefa, reconhecer as conexões essenciais, que permitem a conformação da comunidade e das relações dessa comunidade com o gênero humano. É sob essa tarefa típica que o jornal é convocado a oferecer as percepções necessárias para o reforço e a criação dos nexos da comunidade para a qual reporta.

Ao caracterizar a universalidade como um tipo ideal, Groth não tenta apagar os “poréns” existentes na qualidade do jornal. O autor reforça a existência de dificuldades na apresentação dos conteúdos associados à cultura da qual o jornal faz parte. "As paixões e egoísmos, as mentiras e as incitações do jornal são reflexo da mentalidade das coletividades e dos poderes que o dominam” (GROTH, 2011, p. 221).

O jornal, portanto, agarra tudo o que faz parte do mundo diante dos seus leitores: muitas vezes agarrando de fato errado e deixando lacunas, nem sempre imediata e consequentemente, muitas vezes duvidando e hesitando, impedindo por questões externas ou contrariando a si próprio, atentando só em um estágio tardio, atento e movido por alguma ocasião especial, por alguma pressão, por um motivo atual qualquer, mas, apesar de tudo, sempre sujeito a lei da universalidade e seguindo as suas regras.

Ao observar o conteúdo dos jornais, Groth destaca que, para ter importância para a comunidade na qual está inserido, o jornal precisa tratar de assuntos de forma ampla. O caráter universal do jornal está justamente na capacidade de atender as necessidades dos leitores situados no tempo e no espaço. Por fim, destaca-se a compreensão de que cada característica descrita faz sentido quando está associada às outras. "A mentalidade do editor e do jornalista deve estar voltada para a universalidade não menos do que para a periodicidade, para a atualidade e para a publicidade” (GROTH, 2011, p. 217).

\section{Atualidade}

O debate sobre como a atualidade é um valor para o jornalismo, é um eixo dentro dos tipos ideais materializados por Groth (2011). É uma qualidade do jornal, é um conceito de tempo, do conteúdo do jornal e indica uma quantidade de tempo. Atualidade está ligada, para Groth, com o presente imediato.

Esta característica tem dupla significação: atualidade pode ser compreendida como o que de fato aconteceu, com o real, o efetivamente ocorrido; como também pode ser compreendida como "neste momento”, em voga, atuante no presente. Para Groth, as Ciências dos Jornais analisam o segundo sentido, que trata do "atuante no presente", da mediação como tarefa do jornal. 
Ainda que tenha uma relação com a definição expressa, Groth preocupa-se em não confundir a atualidade com a novidade. "A ligação entre ambos os significados ou grupo de significado é produzido pelo fato de o presente se manifestar como o único, o propriamente real” (GROTH, 2011, p. 223). A novidade também vai ser um elemento do atual, mas não é o único.

A novidade, em contrapartida, não é propriamente um conceito temporal, mas apenas significa que o sujeito não sabia disso. É novo tudo o que o sujeito desconhecia e que passa a conhecer. É, pois, uma relação de qualidade entre o sujeito cognoscente e o objecto conhecido (FIDALGO, 2004, p. 7).

O atual trabalha com as possibilidades do dar a conhecer na perspectiva do presente, passado e futuro. A temporalidade do presente pode ser menor ou maior. Trata-se de reconhecer que o passado o sujeito já conhece, no entanto, os substratos do presente são apresentados pelo jornal. "A revisão do passado e a previsão do futuro são condicionadas pela vivência do presente. É deste, por isso, que o jornal tem de dar notícia” (FIDALGO, 2004, p. 7). No presente, está a ênfase observada para o entendimento do que é a atualidade. Ao situar no tempo e no espaço a tomada de decisões dos leitores, o jornal depende da atualidade para garantir sua existência social. “A razão da atualidade está na necessidade da vida das pessoas, na natureza teleológica da sua psique e na necessidade constante de informações o mais rápido possível sobre os respectivos mundos diante de si, o que também levou à invenção do jornal (GROTH, 2011, p. 236).

Neste aspecto, Groth (2011) relaciona a atualidade do jornal com a simultaneidade, a menor distância entre o fato e a mediação do fato. $\mathrm{O}$ tempo decorrido entre a ocorrência do fato e sua publicação deve se aproximar ao máximo de zero. O conceito de atualidade também pode associar a velocidade e a revelação. "Sendo uma relação temporal a actualidade tem uma dimensão quantitativa que é o espaço de tempo entre o momento da ocorrência e o momento da publicação" (FIDALGO, 2004, p. 7).

O autor demonstra, ainda, que a atualidade está orientada pelas características culturais em que o jornal está inserido. As condições pelas quais um conteúdo é atual será determinada pela sua dependência com a universalidade, na relação do presente, com o passado e o futuro. O presente pode ser ampliado a partir das necessidades e sua ligação com o interesse dos sujeitos. "Uma notícia só é atual para nós - ainda que ela possa nos dar informações dos acontecimentos mais recentes e ser tão novas para nós - se cair no círculo dos nossos interesses gerais momentâneos” (GROTH, 2011, p. 244). A Figura 1, realizada pelo autor, oferece uma síntese de como a atualidade tem variação e dependência com a universalidade. Observa-se, ainda, que a periodicidade vai estender ou diminuir a simultaneidade no jornal, mantendo, portanto, o caráter relacional das características manifestas por Groth. 
Figura 1 - Atualidade na relação com a Universalidade

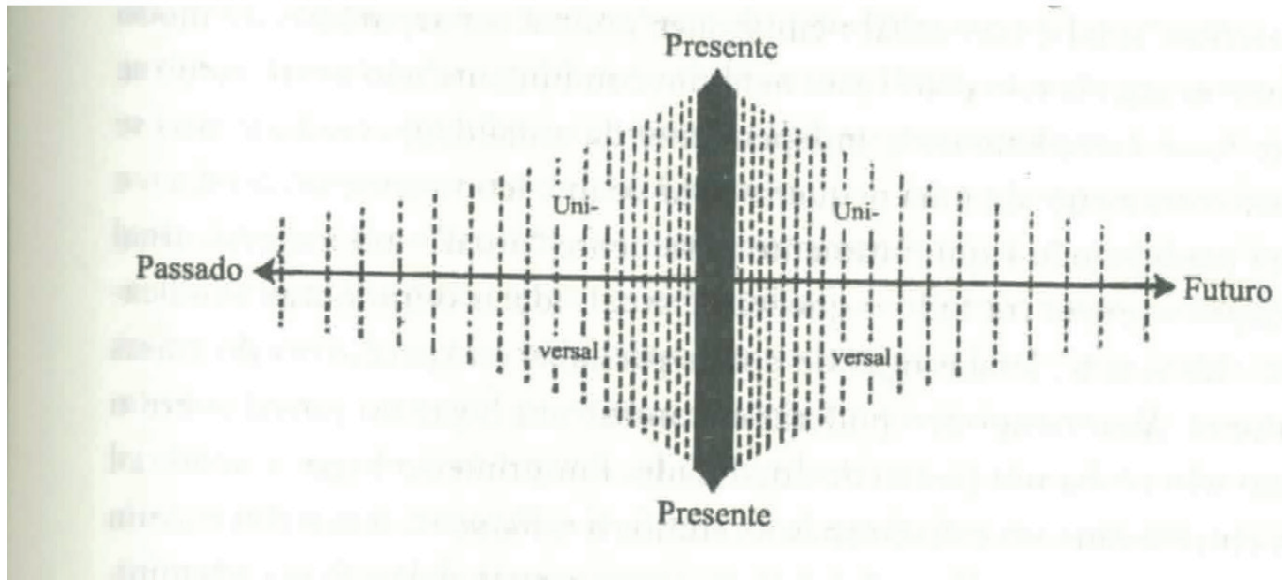

Fonte: Groth (2011).

\section{Publicidade}

A quarta e a última característica descrita por Groth (2011) faz referência à forma do jornal, assim como a periodicidade. A publicidade diz respeito à difusão, à circulação de determinado jornal, do tornar aberto, tornar público. A publicidade está articulada também com a universalidade. "Há uma correspondência directa entre estas duas tendências do jornal, ser universal e dirigir-se a todos” (FIDALGO, 2004, p. 9). A acessibilidade do jornal é o que caracteriza sua publicidade. Há uma relação direta entre abrangência do maior público possível e sua universalidade, pois questões temáticas específicas restringem o interesse e circulação de um jornal.

Assim como no conceito de atualidade, Groth (2011, p. 265) destaca o caráter duplo do significado de publicidade. "[...] tanto de propagação e conhecimento do tema (publicidade atual) quanto a de acessibilidade geral (publicidade potencial) [...]”. O ato de propagar pode ser interpretado também como distribuição, com número de impressos e modelos de circulação. Cabe enfatizar, mais uma vez, que o conceito de publicidade tem estreita relação com a circulação das ideias que motivam um jornal, pela amplitude do sentido e pela retroalimentação da necessidade social do jornalismo com o atendimento a essa necessidade.

Em um primeiro momento, o debate de se tornar público esteve ligado ao liberalismo, contra o estado absolutista (GROTH, 2011). Ao defender o tornar público como um valor no jornal, Groth estabelece a relação com o Estado liberal e defende o jornal liberal e a necessidade dos anúncios para a manutenção da empresa jornalística. Por outro lado, editores e redatores devem colocar em primazia a característica de publicidade do jornal, 
da vinculação do jornal com seu público, e não reduzir ou suprimir essa acessibilidade por causa de interesses dos anunciantes.

As editoras e as redações têm que reservar para si a admissão de contribuições para as seções de textos como de anúncios e a escolha de seus colaboradores exatamente em nome do interesse do público, e sobretudo nunca se questionar o direito do editor de recusar anúncios que contradigam a postura básica política, econômica, religiosa e moral de seu jornal (GROTH, 2011, p. 269).

Da mesma forma que as outras características do jornal, a publicidade também está ligada ao tempo histórico em que a obra jornal está inserida, portanto, a compreensão dela também vai sofrer alterações. "O limiar de publicidade não é algo que permanece o mesmo historicamente, o espaço jornalístico muda sob condições têmporo-espaciais” (GROTH, 2011, p. 279). Significa compreender que as questões culturais exercem influência em como o jornal vai se relacionar com seu público, como ele vai fazer para chegar até seu público.

Para determinar como ocorre a extensão da circulação de um jornal, é preciso reconhecer o grau de universalidade. Groth (2011) reconhece a existência de, pelo menos, três tipos de jornal com características específicas de publicidade - baseado em sua experiência com a imprensa alemã: jornal político nacional, o jornal político estadual e o jornal local. O autor aponta que a existência de uma estrutura com essas características nos "grandes Estados com imprensas completamente desenvolvidas irá formar-se de forma mais clara possível nos Estados liberais” (GROTH, 2011, p. 295).

Por sua vez, o conceito de atualidade está relacionado ao de publicidade com a entrada e saída de conteúdos na empresa jornalística.

O significado fundamental da publicidade resulta sem mais nem menos do fato de que ela é a porta através da qual os bens imateriais do jornal são enviados e recebidos, através da qual todas as seções de produção da empresa, dos escritórios da direção da editora e da redação até s salas de máquinas e o empacotamento, mantém ligação com o mundo exterior (GROTH, 2011, p.313 - Grifos do autor).

A relação com esse mundo exterior está ligada também à necessidade de observar o jornal como empresa, que tem leitores, que tem anunciantes. $\mathrm{O}$ autor revela preocupações com a diagramação, com os anúncios, com as formas de circulação de cada exemplar, para determinar como o jornal está inserido em determinado local, ou cultura. Por fim, entender a publicidade, o ato de chegar ao leitor, como eixo, reforça e reconfigura as outras características do jornal, porque reafirma a necessidade de considerá-las em conjunto para descrever o que o jornal é e o correspondente ao sentido que emana. 


\section{Considerações}

Ao longo do percurso, buscamos reforçar a filiação teórica neokantiana da teoria proposta por Otto Groth. Ao entender as ciências do espírito, torna-se possível compreender a circunscrição que o autor faz sobre o jornalismo como um produto cultural, também da ciência jornalística que se especializa. Ao analisar as vinculações que o autor estabelece das características do jornalismo com a cultura, demonstramos o jornal como materialização especializada de sentidos presentes na sociedade. Ou seja, o autor se propõe a fazer uma dissecação das camadas que conectam o jornal com a sociedade, com o indivíduo. É sob esse escopo que apresentamos as características dos jornais: periodicidade, atualidade, universalidade e publicidade.

Ao descrever as características do jornal, o autor reconhece que os limites entre as características são menos evidentes, dependendo da inserção cultural. "Como em todas as obras culturais, os limites entre as formas descritas aqui são fluidos” (GROTH, 2011, p. 304). Cada eixo descrito poderá sofrer interferências da realidade e do contexto de produção do jornal. Ou seja, Groth não limita o conceito de jornal a apenas um contexto geográfico e histórico, mesmo apresentando características da essência pertinente à construção da ciência jornalística.

Ao estabelecer o jornal como produto da cultura, Groth não restringe sua análise às materializações dos jornais. Além disso, sustenta que os elementos que se materializam no jornal são resultados da comunidade e do tempo nos quais estão inseridos. Consolida, portanto, uma visão que toma o jornal como produto de sentidos socialmente construídos, mutantes historicamente, mas não individualizados suficientemente a ponto de não revelar regularidades. Groth trata de essência do jornalismo com um projeto eminentemente subjetivista e culturalista. As características dos jornais não podem, portanto, servir de catalogação mecânica, sem considerar as teias que conectam o jornalismo com seu público.

\section{Referências}

BUENO, W. C. O jornalismo como disciplina científica: a contribuição de Otto Groth. São Paulo: ECA, 1972.

DILTHEY, W. Introduccion a las Ciencias del Espiritu. En la que se trata de fundamentar el estudio de la sociedad y de la historia. Cidade de México: Fondo de Cultura Economica, 1949.

DILTHEY, W. A compreensão dos outros e das suas manifestações de vida. In: GARDINER, P. Teorias da Histórias. $3^{\mathrm{a}}$ Edição. Lisboa: Calouste Guberkian, 1968. p. 259-271.

FAus Belau, A. La Ciencia Periodistica de Otto Groth. Pamplona: Instituto de Periodismo de la Universidad de Navarra, 1966.

FIDALGO, A. Jornalismo online segundo o modelo de Otto Groth. Pauta Geral, n. 6, 2004. Disponível em: http://www.bocc.ubi.pt/pag/fidalgo-groth-jornalismo-online.pdf. Acesso em: 22 jul. 2018.

GROTH, O. O poder cultural desconhecido: fundamento da Ciência dos Jornais. Petrópolis: Vozes, 2011. 
LUKÁCS, G. A ontologia do ser social I. São Paulo: Boitempo, 2012.

OLIVEIRA, H. M. G. Fundamentos para a ciência do Jornalismo: bases conceituais a partir de Weber e Groth. In: ORNAMESE, F.; BAZI, R. Reflexões para o ensino de jornalismo no Brasil: algumas abordagens. Campinas: FNPJ, 2014.

PONTES, F. S. Teoria e História do Jornalismo: desafios epistemológicos. Dissertação (Mestrado em Jornalismo), Programa de Pós-Graduação em Jornalismo, Centro de Comunicação e Expressão, Universidade Federal Santa Catarina, Florianópolis, 2009.

REIS, J. C. Willem Dilthey e a autonomia das ciências histórico-sociais. Londrina: Eduel, 2003.

RÜDIGER, F. Origens do pensamento acadêmico em jornalismo: Alemanha, União Soviética e Japão. Florianópolis: Insular, 2017.

\section{Cintia Xavier}

Professora do Programa de Pós-Graduação em Jornalismo da Universidade Estadual de Ponta Grossa. Doutora em Ciências da Comunicação pela Unisinos. Lidera o Grupo de Pesquisa Lógicas de Produção e Consumo no Jornalismo. E-mail: cintia_xavierpg@yahoo.com.br.

\section{Felipe Simão Pontes}

Professor do Programa de Pós-Graduação em Jornalismo e da Pós-Graduação em Ciências Sociais Aplicadas da Universidade Estadual de Ponta Grossa. Lidera o Grupo de Pesquisa Jornalismo, Conhecimento e Profissionalização. Autor do livro “Adelmo Genro Filho e a Teoria do Jornalismo”. E-mail: felipesimaopontes@gmail.com.

Recebido em: 10.09.2018

Aprovado em: 22.05.2019

Este artigo é publicado em acesso aberto (Open Access) sob a licença Creative Commons Attribution Non-Commercial (CC-BY-NC), que permite uso, distribuição e reprodução em qualquer meio, sem restrições, desde que sem fins comerciais e que o trabalho original seja corretamente citado.

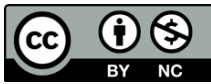

